\title{
BMJ Open Episiotomy practice in six Palestinian hospitals: a population-based cohort study among singleton vaginal births
}

\author{
Kaled Zimmo, ${ }^{1,2}$ Katariina Laine, ${ }^{3,4}$ Erik Fosse, ${ }^{2,5}$ Mohammed Zimmo, 2,6 \\ Hadil Ali-Masri, ${ }^{2,7}$ Manuela Zucknick, ${ }^{8}$ Åse Vikanes, ${ }^{2}$ Sahar Hassan ${ }^{9}$
}

To cite: Zimmo K, Laine $\mathrm{K}$, Fosse E, et al. Episiotomy practice in six Palestinian hospitals: a population-based cohort study among singleton vaginal births. BMJ Open 2018;8:e21629. doi:10.1136/ bmjopen-2018-021629

- Prepublication history for this paper is available online. To view these files, please visit the journal online (http://dx.doi org/10.1136/bmjopen-2018021629).

Received 10 January 2018 Revised 18 May 2018 Accepted 18 June 2018
Check for updates

(C) Author(s) (or their employer(s)) 2018. Re-use permitted under CC BY-NC. No commercial re-use. See rights and permissions. Published by BMJ.

For numbered affiliations see end of article.

Correspondence to

Dr Kaled Zimmo;

drkaledzimmo@gmail.com

\section{ABSTRACT}

Objective To explore the rates, characteristics and indications for episiotomy among women delivering vaginally for the first time, as well as parous women. Study design A prospective, population-based birth cohort study.

Setting Obstetric departments in six Palestinian government hospitals.

Participants All women with singleton vaginal births ( $n=29$ 165) from 1 March 2015 until 1 March 2016.

Methods All women were divided into two groups: first vaginal birth group ( $\mathrm{n}=9108)$, including primiparous women and women with their first vaginal birth after one caesarean section, and the parous group ( $n=20057)$. Each group was analysed separately. Data were presented as numbers and percentages or range. Differences in rates were assessed by the $p$ values of $\chi^{2}$ test, or Fisher's exact test if there are cell counts less than 5 .

Main outcome measures Episiotomy rates and indications among women of singleton births.

Results The overall episiotomy rate was $28.7 \%$ : $78.8 \%$ for women with first vaginal birth (range 56.6\%-86.0\%) and $5.9 \%$ for parous women (range $1.0 \%-9.5 \%$ ). The most common indications for episiotomy were 'primiparity' in the first vaginal birth group (69.9\%) and 'protecting the perineum' in the parous group (59.5\%). The least common indications were prolonged second stage $(1.5 \%)$ and fetal distress $(6.9 \%)$, respectively.

Conclusion In Palestine, the majority of women who delivered vaginally for the first time had an episiotomy. Education of birth attendants, clinical audits, educational interventions and adherence to the updated guidelines may help to decrease the routine overuse of episiotomy.

\section{INTRODUCTION}

Episiotomy was introduced across Europe in 1742, as widening of the vaginal opening was believed to accelerate labour, protect the fetal head and prevent severe obstetrical anal sphincter injuries (OASIS). ${ }^{1}$ Nowadays, there is general agreement on the restrictive use of episiotomy. Although episiotomy should be done only when indicated, many countries still practise it routinely. ${ }^{23}$ However, some possible complications, such as wound infection, wound dehiscence, blood loss,

\section{Strengths and limitations of this study}

This study is the largest, prospective, population-based cohort study in Palestine that includes hospitals from different geographical areas in both Gaza and the West Bank, and thus allowed a comprehensive insight into episiotomy practice in Palestine.

- All singleton pregnant women aiming to give birth vaginally in six study hospitals were included, reducing the risk of selection bias.

- The study included six government hospitals in Palestine and most of the deliveries occur in government hospitals, making the findings of the study representative.

- Missing data occurred in some variables across the study hospitals, which are expected to be random and therefore not influencing the outcome.

- The study did not include data from private hospitals; even though the number of deliveries is small, this study cannot assess episiotomy practice in these hospitals.

severe pain and the risk of OASIS, ${ }^{3}$ have led to efforts to reduce the overuse of episiotomy, which started more than 30 years ago. ${ }^{4}$ Additionally, many studies have reported that the rate of perineal tears may increase with routine episiotomy use. ${ }^{35}$

The rates of episiotomy vary between countries. ${ }^{6}$ One European study reported episiotomy rates from $3.7 \%$ in Denmark to $75 \%$ in Cyprus. ${ }^{7}$ In Arab countries the rates of episiotomy are still high: $41.4 \%$ in Jordan, ${ }^{8} 52.2 \%$ in Saudi Arabia, ${ }^{9} 62 \%$ in Lebanon and $64 \%$ in United Arab Emirates. ${ }^{10}$

There are few studies exploring the rates of episiotomy in Palestine. One was an observational hospital-based study between 2002 and 2003, which reported that six out of eight Palestinian government hospitals routinely used episiotomy in primiparous women. ${ }^{11}$ Another, based on the data obtained from the Palestinian Central Bureau of Statistics, showed that the overall episiotomy rate 
in Palestine in 2004 was $13.9 \% .^{12}$ Furthermore, after the implementation of educational interventions aiming to prevent overuse of episiotomy in one maternity unit in Palestine, the rates of episiotomy decreased between 2005 and 2010 , from $80 \%$ to $39.1 \%$ among primiparous women and from $5.8 \%$ to $3.4 \%$ among parous women. ${ }^{13}$

Indications for episiotomy vary between countries and are influenced by the opinion of the clinician in charge of the delivery. ${ }^{14}$ Primiparity, instrumental delivery, fetal malpresentation, fetal distress, large fetal size, breech delivery, shoulder dystocia and rigid perineum are the most common indications reported for episiotomy. ${ }^{15-17}$ The American College of Obstetricians and Gynecologists (ACOG) reported shortening of the second stage of labour and high risk of OASIS as the most frequent indications for episiotomy. ${ }^{14}$

The ACOG,${ }^{14}$ the Royal College of Obstetricians and Gynaecologists (RCOG) ${ }^{18}$ and the National Institute for Health and Care Excellence (NICE) ${ }^{19}$ recommend using episiotomy on clinical indications only. Furthermore, in its most recent publication in 2018, the WHO also suggests restrictive use of episiotomy, although no specific rate is recommended. ${ }^{20}$

The objective of this study was to explore the rates, characteristics and indications for episiotomy in six Palestinian government hospitals.

\section{METHODS}

\section{Study design and settings}

This present prospective, population-based cohort study was conducted between 1 March 2015 and 1 March 2016, and was based on data from an original study called the Palestinian Perineum and Birth Complications Study. The original study was performed between March 2015 and November 2016 including all women admitted for vaginal birth in six government hospitals in Palestine. ${ }^{21}$ The six hospitals-three in Gaza: hospitals 1, 2 and 3; and three in the West Bank: hospitals 4, 5 and 6-were selected according to geographical distribution and the number of deliveries in each hospital. Hospital 5 had been included in a previous study by implementing an intervention to reduce the routine use of episiotomy. ${ }^{13}$ Most deliveries in Palestine occurred in government hospitals; altogether, there were 15 hospitals, with a total annual delivery number of $\mathrm{n}=75$ 891, comprising almost $60 \%$ of all deliveries in Palestine. ${ }^{22}$ This study included six government hospitals with a total annual delivery number of $n=47046$, comprising $61.9 \%$ of all deliveries that occurred in the government sector. ${ }^{22}$ The study design, undertaking and reporting followed the Strengthening the Reporting of Observational Studies in Epidemiology statement for cohort studies.

\section{Data collection and population}

Data were collected prospectively by birth attendants (doctors and midwives) during the whole study period under the authors' supervision (KMZ, MZ, HYA-M, SH) using a specific case registration form $(\mathrm{CRF}) .{ }^{21}$ The content of the CRF was based on previous research published from Palestine, Norway and the WHO. ${ }^{21}$ The CRFs were entered into the web-based medical records called the District Health Information System 2 and subsequently transferred to the Services for Sensitive Data (TSD). The TSD is a specific secure platform developed by Oslo University to be used for collection, storage, analysis and sharing of sensitive data for research purposes to maintain data security and privacy (tsd-drift@usit.uio.no).

The CRF included information on indications for episiotomy, listed as primiparity, instrumental deliveries, fetal distress, prolonged second stage of labour and protecting the perineum. These indications were listed as in the hospital patient forms.

During the study period (from 1 March 2015 to 1 March 2016), 35109 women gave birth. All cases of emergency and elective caesarean sections and multiple gestations were excluded $(n=5944)$. The remaining study sample consisted of 29165 women with singleton vaginal deliveries.

Women were stratified into two groups: one group comprised women with their first vaginal birth, including women who delivered vaginally for the first time after caesarean section; and the other group comprised parous women (women who had one or more vaginal delivery). The selected study population is shown in figure 1 .

\section{Patient and public involvement}

No patients were involved in setting the research question or the outcome measures, nor were they involved in developing plans for the design or implementation of the study. No patients were asked to advise on the interpretation or writing up of the results. There are no plans to disperse the results of our research to study participants or the applicable patient community. However, the findings have informed the most recent edition of the Palestinian National Guidelines for Obstetrics and Gynaecology and will as such enhance evidence-based clinical practice in Palestine.

\section{Variables}

Episiotomy was dichotomised into yes or no (table 1). Indications for episiotomy were categorised into five groups according to hospitals' patient admission forms (table 2). Maternal age was categorised into four groups (tables 3 and 4). Fetal presentation at birth was categorised into three groups according to the presenting part during the delivery (tables 3 and 4 ). The duration of the active second stage of labour in minutes was categorised into 15 min duration groups (tables 3 and 4). Fetal birth weight was classified into five groups (tables 3 and 4 ).

\section{Statistical analysis}

All statistical analyses were performed using SPSS V.22.0. Categorical data were presented as frequencies and percentages, and continuous data were summarised by mean and SD or range. Associations between categorical 


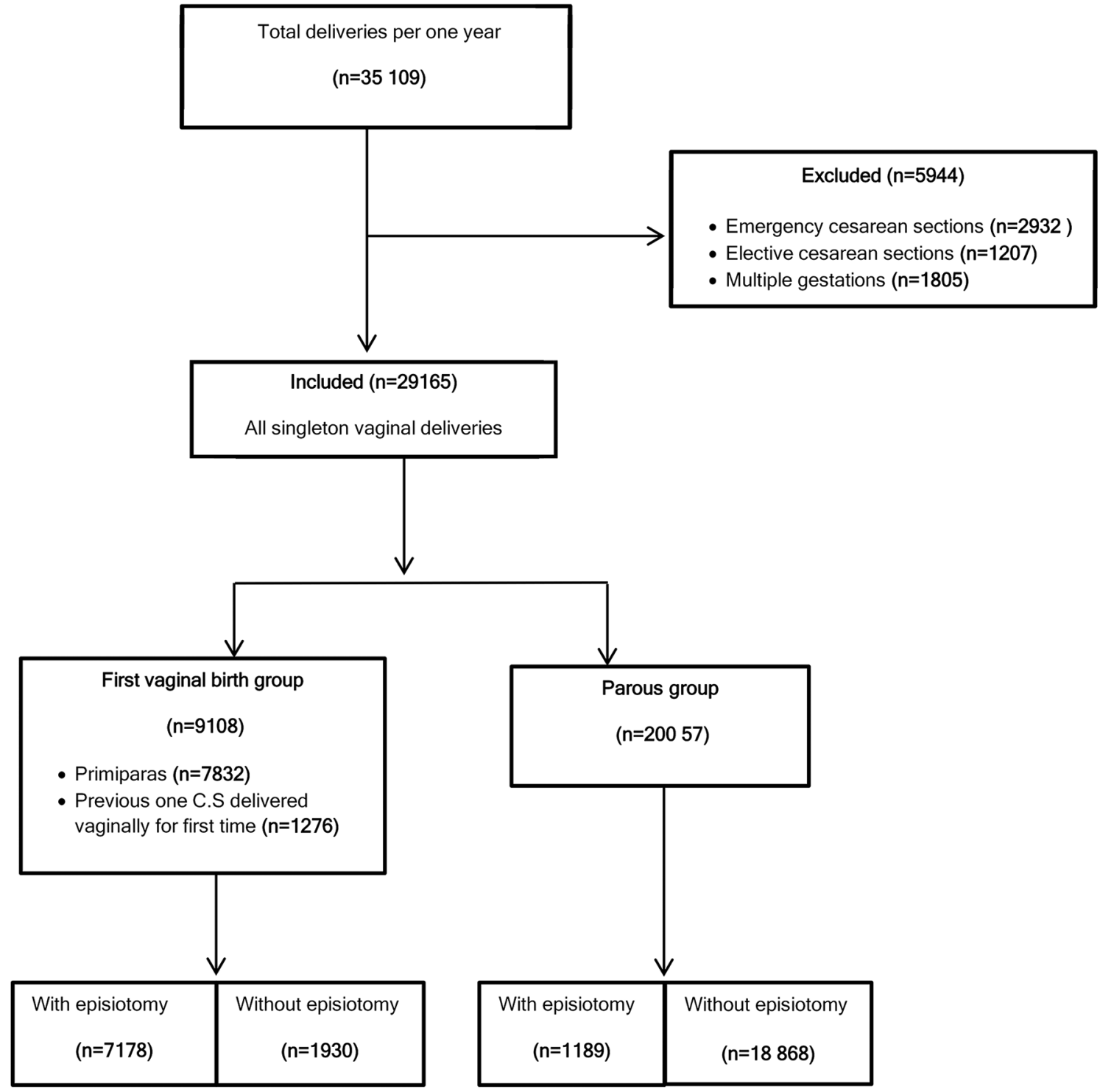

Figure 1 Flow chart of the selected study population. CS, caesarean section.

variables and episiotomy were assessed using Pearson's $\chi^{2}$ tests (or Fisher's exact test, if there are cell counts less than 5). Statistical significance was defined as $p$ values less than the nominal significance level of 0.05 . All statistical tests were performed as two-sided tests.

\section{RESULTS}

In total, 29165 women with singleton vaginal birth were included in this study $(83.1 \%$ of the total sample). Of these women, 9108 (31.2\%) were in the first vaginal birth group, of whom $7832(26.8 \%)$ were nulliparous and $1276(4.4 \%)$ underwent their first vaginal birth after one caesarean section. The parous group comprised 20057 $(68.8 \%)$ women.

The overall episiotomy rate was $28.7 \%$ (ranging from $20.0 \%$ to $35.2 \%$ ). The rates of episiotomy varied between hospitals, yet the rates were higher in Gaza hospitals. The overall episiotomy rate was highest in hospital 3 with 3454 $(35.2 \%)$ and lowest in hospital 5 with 617 (20\%).
In the first vaginal birth group, the rate of episiotomy was $78.8 \%$ (ranging from $56.8 \%$ to $86.0 \%$; $\mathrm{n}=7178$ ), and $77.3 \%$ of primiparous women and $88.1 \%$ of women undergoing the first vaginal birth after caesarean section had an episiotomy. In the parous group, the overall rate of episiotomy was $5.9 \%$ (ranging from $1.0 \%$ to $9.6 \%$; $\mathrm{n}=1189)$ (table 1).

\section{First vaginal birth group}

The most common indication was 'primiparity', where the highest proportion was found in hospital 1 with $79.9 \%(\mathrm{n}=863)$ and the lowest proportion in hospital 5 with $38.2 \%(\mathrm{n}=227)$. The least common indication was 'prolonged second stage of labor' (ranging between hospitals from $0.7 \%$ in hospital 3 and $4.5 \%$ in hospital 5 ) (table 2).

In this group, the mean age was 23.5 years (range: 15.0-38.0 years) and the mean duration of the active second stage of labour was $13.4 \mathrm{~min}$ (ranging from 9.3 to $19.0 \mathrm{~min})$. Almost all women had a cephalic 
Table 1 Rates of episiotomy by parity and hospitals between March 2015 and March 2016 ( $N=29$ 165)

\begin{tabular}{|c|c|c|c|c|c|}
\hline \multirow[b]{2}{*}{ Hospitals } & \multirow{2}{*}{$\begin{array}{l}\text { Total episiotomy } \\
\text { rate } \mathrm{n}(\%)^{\star}\end{array}$} & \multicolumn{2}{|c|}{ First vaginal birth group $+(\mathbf{n = 9 1 0 8 )} \mathbf{n}(\%)$} & \multicolumn{2}{|c|}{ Parous group $\neq(n=20057) n(\%)$} \\
\hline & & Episiotomy & No episiotomy & Episiotomy & No episiotomy \\
\hline Gaza $(n=18$ 666) & 5873 (31.5) & 4798 (81.9) & $1062(18.1)$ & $1075(8.4)$ & 11731 (91.6) \\
\hline Hospital 1 (n=4475) & $1378(30.8)$ & $1080(81.0)$ & $253(19.0)$ & $298(9.5)$ & $2844(90.5)$ \\
\hline Hospital 2 ( $n=4382)$ & $1041(23.7)$ & $891(71.9)$ & $349(28.1)$ & $150(4.8)$ & $2992(95.2)$ \\
\hline Hospital 3 (n=9809) & 3454 (35.2) & $2827(86.0)$ & $460(14.0)$ & $627(9.6)$ & $5895(90.4)$ \\
\hline West Bank ( $n=10$ 499) & $2494(23.7)$ & $2380(73.3)$ & $868(26.7)$ & $114(1.6)$ & $7137(98.4)$ \\
\hline Hospital 4 ( $n=5108)$ & $1348(26.4)$ & $1299(82.4)$ & $278(17.6)$ & $49(1.4)$ & $3482(98.6)$ \\
\hline Hospital 5 (n=3077) & $617(20.0)$ & $596(56.8)$ & $453(43.2)$ & $21(1.0)$ & 2007 (99.0) \\
\hline Hospital 6 ( $n=2314)$ & $529(22.9)$ & $485(78.0)$ & $137(22.0)$ & $44(2.6)$ & $1648(97.4)$ \\
\hline Total (N=29 165) & 8367 (28.7) & 7178 (78.8) & 1930 (21.2) & $1189(5.9)$ & 18868 (94.1) \\
\hline
\end{tabular}

$\mathrm{n}=$ valid number.

*(\%=total episiotomy/total vaginal deliveries in each hospital).

†First vaginal birth group: included previous one caesarean section with first vaginal birth (number of previous one caesarean section who delivered vaginally=1276; out of these 1125 women delivered with episiotomy).

‡Parous group: included women with second or subsequent vaginal births.

presentation at birth $(95.9 \%)$, and only $3.8 \%$ delivered babies weighing $\geq 4000 \mathrm{~g}$ (table 3 ).

\section{Parous group}

Within the parous group, the most common indication was 'protecting the perineum' (ranging from $38.1 \%$ in hospital 5 to $88.6 \%$ in hospital 6). The least common indication was 'fetal distress' (ranging from 2.0\% in hospital 4 to $10.7 \%$ in hospital 1) (table 2).

In this group, the mean age was 27.6 years (ranging from 17.0 to 45.0 years) and the mean duration of the active second stage of labour was $11 \mathrm{~min}$ (range 6.2-16.0 min). Almost $97.5 \%$ had a cephalic presentation at birth and only $8.6 \%$ delivered babies weighing $\geq 4000 \mathrm{~g}$ (table 4 ).

\section{DISCUSSION}

The overall episiotomy rate in six Palestinian government hospitals was almost $30.0 \%$. Episiotomy was used for the majority of women who delivered vaginally for the first time, and the most common indication for episiotomy among primiparous women was 'primiparity.' Among

Table 2 Indications for episiotomy by hospitals and parity

First vaginal birth group with episiotomy* $(n=178), n(\%)$

\begin{tabular}{|c|c|c|c|c|c|c|c|}
\hline Indications of episiotomy & $\begin{array}{l}\text { Total } \\
\text { episiotomy } \\
\text { indications } \\
\text { n (\%) }\end{array}$ & $\begin{array}{l}\text { Hospital } 1 \\
(n=1080)\end{array}$ & $\begin{array}{l}\text { Hospital } 2 \\
(n=891)\end{array}$ & $\begin{array}{l}\text { Hospital } 3 \\
(n=2827)\end{array}$ & $\begin{array}{l}\text { Hospital } 4 \\
(n=1299)\end{array}$ & $\begin{array}{l}\text { Hospital } 5 \\
(n=596)\end{array}$ & $\begin{array}{l}\text { Hospital } 6 \\
(n=485)\end{array}$ \\
\hline Protecting the perineum & $1316(18.3)$ & $95(8.8)$ & $191(21.4)$ & $376(13.3)$ & $360(27.7)$ & $257(43.1)$ & $37(7.6)$ \\
\hline Fetal distress & $272(3.8)$ & $38(3.5)$ & $18(2.0)$ & $76(2.6)$ & $94(7.2)$ & $43(7.2)$ & $3(0.5)$ \\
\hline Instrumental delivery & $285(4.0)$ & $44(4.1)$ & $24(2.7)$ & $68(2.4)$ & $102(7.8)$ & $21(3.5)$ & $26(5.4)$ \\
\hline Primiparity & 5019 (69.9) & $863(79.9)$ & $624(70.0)$ & 2241 (79.3) & $693(53.4)$ & 227 (38.2) & $371(76.6)$ \\
\hline Missing & $181(2.5)$ & $22(2.0)$ & $28(3.1)$ & $50(1.7)$ & $18(1.4)$ & $21(3.5)$ & $42(8.7)$ \\
\hline
\end{tabular}

Parous group with episiotomy† (n=1189), n (\%)

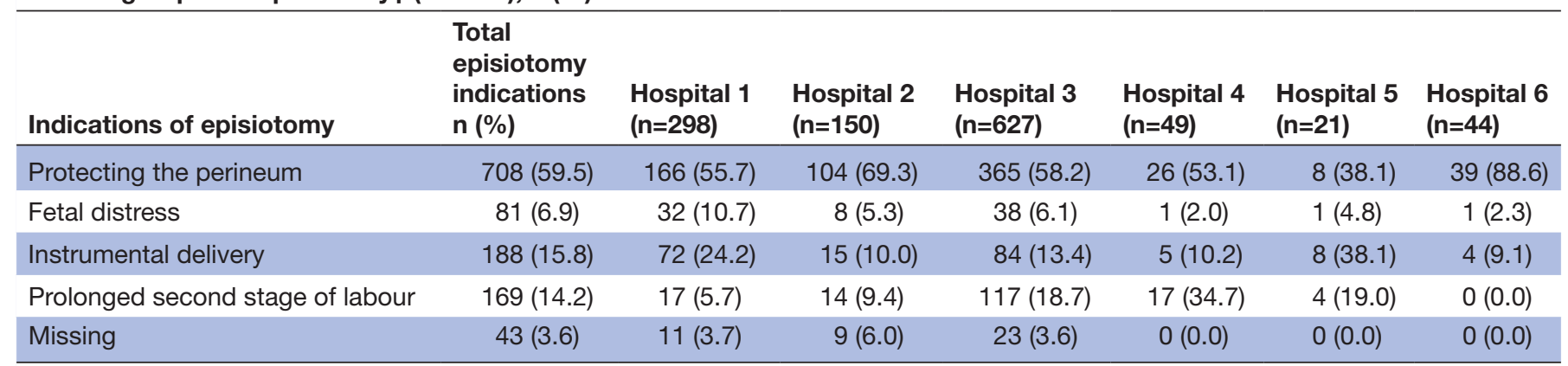

*First vaginal birth group included previous one caesarean section with first vaginal birth.

†Parous group included women with second or subsequent vaginal births. 


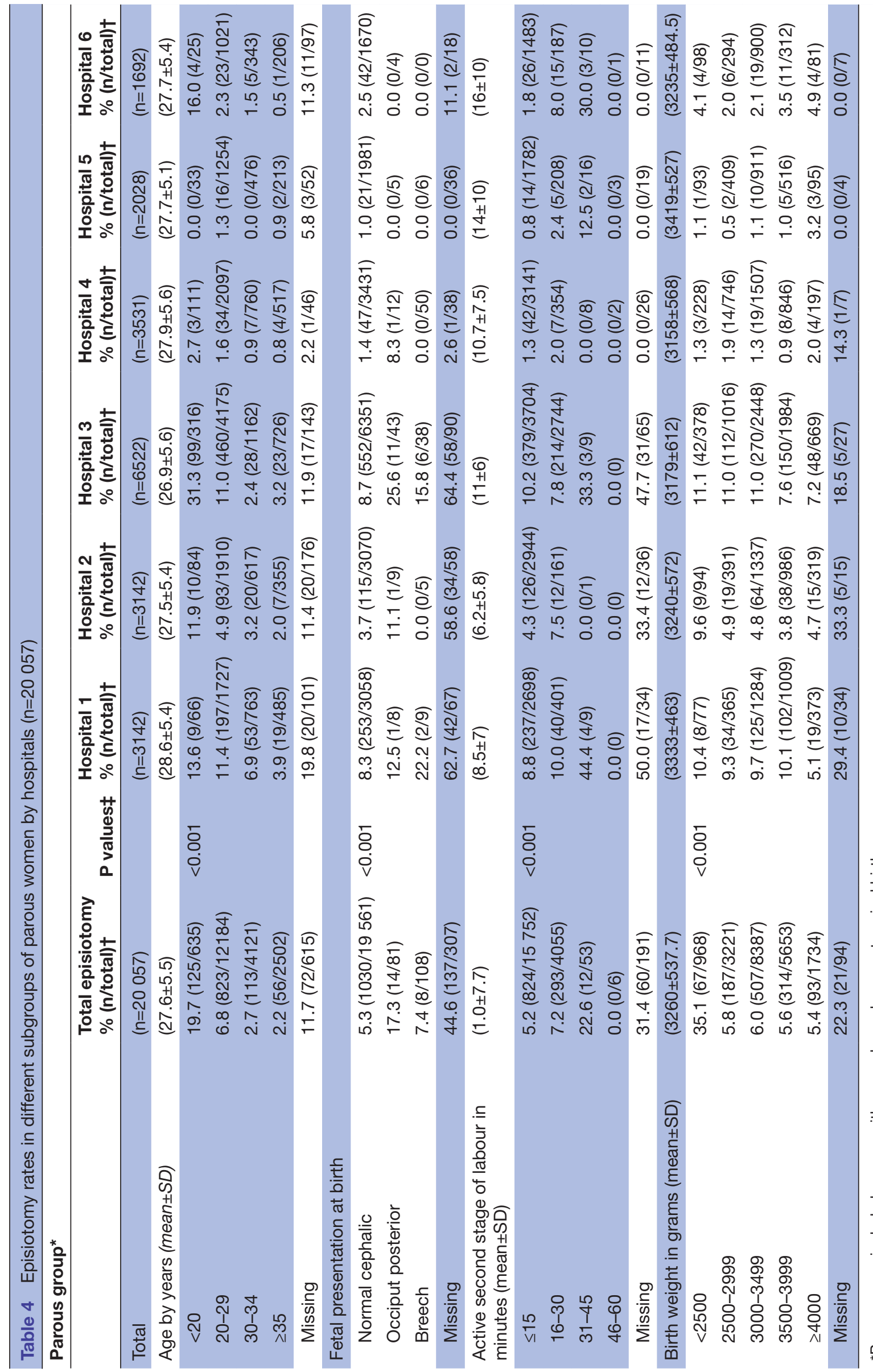

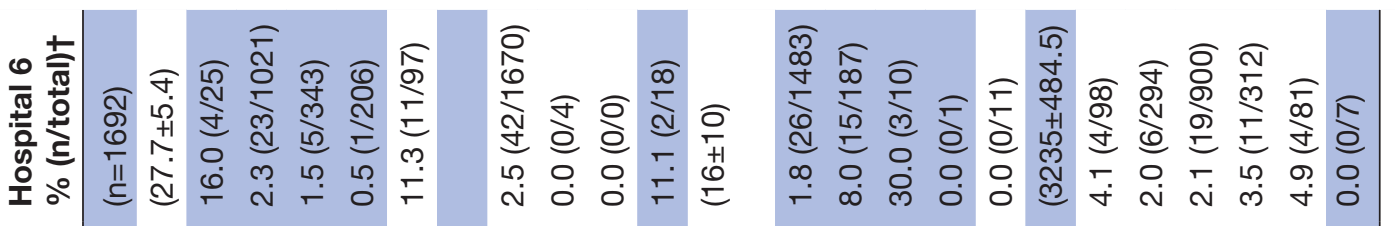

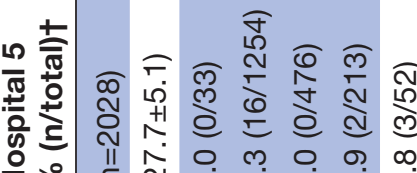
$\widehat{\infty}$

$\Sigma \sqrt{2} 0$ à 9 อे 일

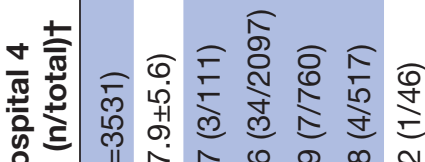
$\widehat{\overline{9}}$

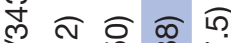

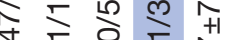
$\checkmark m$ o 0 (1) ஓ

ल

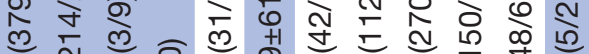
$n$ m 우 ભำ

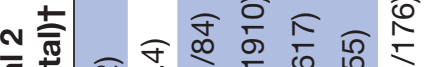

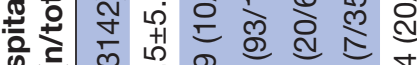

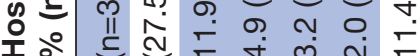

$\tau$. 0 
parous women, the rate of episiotomy was notably lower, and the most frequent indication was 'protection of the perineum'. These findings show that the present clinical practice of episiotomy use in Palestine is not in line with the international guidelines and recommendations, such as the ACOG ${ }^{14}$ the RCOG international guidelines ${ }^{18}$ or the WHO recommendations. ${ }^{20}$

Episiotomy rates and their indications varied across the study hospitals, which may reflect differences in the levels of experience and attitudes of the medical staff. However, one hospital (hospital 5) stood out, having a significantly lower rate of episiotomy than the others by almost $60 \%$. This might be the result of long-term efforts to prevent overuse of episiotomy in this hospital. ${ }^{13}$ In comparison, the current rate of episiotomy in hospital 5 is considered high when compared with the previous study, which may indeed reflect the need for continuous education and training of birth attendants to maintain low episiotomy rates.

Similarly, wide variations in episiotomy rates exist around the world as an expression of the difference in routine episiotomy use between countries, as well as within countries and among birth attendants with the same level of experience ${ }^{67}$ In this study, the overall episiotomy rate was $28.7 \%$, which is considered high at almost twofold above the last reported rate at $13.9 \%$ by the Palestinian Central Bureau of Statistics in 2004. ${ }^{12}$ These differences could reflect the increasing number of births in Palestine with crowded hospitals and insufficient number of beds available in maternity units. Additionally, the decrease in the number of medical staff compared with the number of births could prompt some birth attendants to try to accelerate the delivery by using episiotomy, regardless of the negative maternal health impact of this procedure.

The rates of episiotomy among primiparous women in different countries ranged from $15.0 \%$ in Sweden up to $100 \%$ in Guatemala. ${ }^{6}$ In Arab countries, the rates of episiotomy in primiparous women were $51.2 \%$ in Saudi Arabia, ${ }^{9}$ $91 \%$ in Jordan ${ }^{8}$ and $95 \%$ in Qatar. ${ }^{23}$ In comparison, the rate of episiotomy among primiparous women in this study was $77.3 \%$, reflecting the routine use of episiotomy by most physicians and midwives, regardless of national ${ }^{24}$ and international guidelines. ${ }^{19}$ Moreover, a recent study from Palestine concluded that knowledge of the anatomy, types of episiotomy and best methods of episiotomy repair among physicians and midwives was inadequate. ${ }^{25}$ Although the rates of episiotomy among women having their first vaginal birth appeared to be lower than those in studies from Qatar and Jordan and more than in Saudi Arabia, this may not be the case. The aforementioned studies may not present the real rates of episiotomy in these countries, as they included only a limited number of births in one or two hospitals. In contrast, the present study included six major maternity hospitals representing $62 \%$ of all births taking place in government hospitals in Palestine. Globally, the rates of episiotomy among parous women are reported to be notably lower compared with primiparous women, ranging from $3.4 \%$ in Brazil up to
$48.0 \%$ in Indonesia, while in some Eastern Asian countries, such as in China, they remain very high at $71.4 \%{ }^{6}$ Findings of the current study show the rates of episiotomy among parous women are in line with the global rates. The possible reasons for less use of episiotomy among parous women could be more elasticity of the perineum, a shorter active second stage of labour and the fact that parous women are associated with less obstetric complications during vaginal delivery. ${ }^{5}$

There is no general agreement on the indications for episiotomy, ${ }^{16}$ and various studies included acute fetal distress, instrumental deliveries, shoulder dystocia, fetal malpresentation, poorly healed OASIS and primiparity as possible indications. ${ }^{15-17}$ However, the RCOG, the ACOG and the WHO recommended that episiotomy must be used only on clinical indications. Several variations in episiotomy indications were advocated; the RCOG recommended instrumental deliveries to be the only possible indication, ${ }^{18}$ the ACOG stated that episiotomy use depended on clinical judgement of the birth attendants, ${ }^{14}$ while the WHO listed that episiotomy in obstetric emergencies, such as fetal distress requiring instrumental vaginal birth, could be a presumed indication for episiotomy. ${ }^{20}$

In Palestine, hospital guidelines and protocols state clearly that episiotomy is to be performed only if indicated, but do not include a list of indications. ${ }^{24}$ However, in practice, primiparity is still the most common indication for episiotomy, followed by protecting the perineum, instrumental deliveries, fetal distress and prolonged second stage of labour. This practice is an expression of widespread non-evidence-based episiotomy use among obstetricians in Palestine as they still believe that the routine use of episiotomy among primiparous women can protect them from OASIS, confounded by the lack of clear and agreed indications for episiotomy. Furthermore, doctors in Palestine have no insurance against occupational errors, which may lead them to exercise extreme caution to avoid the risks that may occur during childbirth for fear of legal liability. Additionally, a study from Palestine reported that routine practices, like episiotomy, depend on the style and experience of the head obstetrician rather than the updated guidelines. ${ }^{11}$

Conflicting results on the relationship between maternal age and episiotomy are found in previous research; one study reported that the rate of episiotomy increased above 35 years of age. ${ }^{16}$ However, another study did not confirm this trend, ${ }^{5}$ as it used elasticity and non-elasticity of the perineum as the criteria to decide for episiotomy rather than age. However, the number of women who were 35 years or older was low in this study, since most obstetricians in Palestine tend to deliver primiparous women above 35 years by caesarean section. ${ }^{26} \mathrm{An}$ increased neonatal birth weight is usually associated with episiotomy. ${ }^{20}$ The results of this study were inconsistent with these findings, confirming the routine use of episiotomy over selective use also in this group. 
Numerous reviews and meta-analyses indicated that there is no evidence supporting the benefits of the routine practice of episiotomy, ${ }^{3}$ which is adopted by the NICE guidelines. ${ }^{19}$ This evidence is not implemented in many countries. Moreover, one study reported that restrictive use of episiotomy did not only decrease the risks for maternal health but was also less costly than its routine use. ${ }^{27}$ Palestine is a country with scarce resources, suggesting that it would be wise to reduce overuse of episiotomy and use it only when clinically indicated. The alarming lack of evidence-based practice in this area has to be addressed by education of staff, regular obstetric clinical audits and team feedback to support greater adherence to updated guidelines by the entire obstetrical team. Additionally, educational interventions to reduce the rates of episiotomy in Palestine are mandatory, as they have been effective in one of the study hospitals. ${ }^{13}$ Furthermore, this study was the largest birth cohort study in Palestine and included six hospitals from different areas including Gaza and the West Bank, which allows a comprehensive insight into the practice of episiotomy in Palestine and may help health leaders in Palestine to find solutions to enhance practice and reduce unnecessary use of episiotomy. This study is also interesting in the global context, as other areas face similar problems. Moreover, a study to explore the risk factors associated with episiotomy in Palestine is needed.

\section{Strengths and limitations of the study}

The strengths of this study are its large sample size and its use of a comprehensive database that includes detailed information on all pregnancies and births scheduled for vaginal delivery; this allows a comprehensive insight into the practice of episiotomy in Palestine. Furthermore, most deliveries in Palestine take place in the government sector, ${ }^{12}$ which makes the study findings representative. Additionally, it is a prospective population-based study, with all women who gave birth vaginally in the study hospitals included, reducing the risk of selection bias.

The limitations of the study include missing data on some variables; the proportion of missing data varied across the study hospitals. Since the missing data were random, it is not believed to affect the outcomes. The data were obtained from six large government hospitals, and those from private hospitals were not included, although the number of deliveries in the private sector is small. Therefore, this study does not allow conclusions on the actual practice of episiotomy in private hospitals. We do not have information on the possible differences in staff qualifications or staff shift patterns in each hospital. However, as all study hospitals are government hospitals, it is justified to assume that no considerable differences exist between them.

\section{CONCLUSION}

The rate of episiotomy is still high in Palestine, as it is routinely done for the majority of women who deliver vaginally for the first time. Non-evidence-based practices related to episiotomy are widespread during birth in Palestine, suggesting that education of birth attendants, adherence to updated guidelines, implementing obstetric clinical audits and interventions are needed to reduce the overuse of episiotomy. Urgent intervention is necessary to curb the trend of the excessive use of episiotomy.

\section{Author affiliations}

${ }^{1}$ Department of Obstetrics, Al Aqsa Hospital, Gaza, Palestine

${ }^{2}$ The Intervention Centre, Oslo University Hospital, Rikshospitalet, Oslo, Norway

${ }^{3}$ Department of Obstetrics, Oslo University Hospital, Oslo, Norway

${ }^{4}$ Department of Health Management and Health Economics, Institute of Health and

Society, University of Oslo, Oslo, Norway

${ }^{5}$ Faculty of Medicine, Institute of Clinical Medicine, University of Oslo, Oslo, Norway

${ }^{6}$ Department of Obstetrics, Al Shifa Hospital, Gaza, Palestine

${ }^{7}$ Department of Obstetrics, Palestine Medical Complex, Ramallah, Palestine

${ }^{8}$ Department of Biostatistics, Oslo Centre for Biostatistics and Epidemiology, University of Oslo, Oslo, Norway

${ }^{9}$ Department of Nursing, Faculty of Pharmacy, Nursing and Health Professions, Birzeit University, Birzeit, Palestine

Acknowledgements The authors would like to extend their sincere gratitude to the Palestinian Ministry of Health for making this study possible. The authors would also like to thank Dr Bettina Böttcher for the English language revision of the manuscript.

Contributors KMZ contributed to conception and design, acquisition of data analysis and interpretation of data, drafting the article, and revising, modifying and integrating the comments received from the coauthors. KL, EF, AV and SH contributed to study design, developing research tool, protocol development, coordination and training, data collection, acquisition of data analysis, conceptualisation of this study, analysis, interpretation, commenting, and revising the manuscript critically for important intellectual content. MWZ and HYA-M contributed to data collection and revised the article critically for important intellectual content. MZ made substantial contributions to the conception, analysis and interpretation of data, and revising the article for important intellectual content. All authors have revised the manuscript and have approved it.

Funding This work was supported by the Norwegian Research Council grant number 234452/14.

Competing interests None declared.

Patient consent Not required.

Ethics approval This study was approved by the Norwegian Data Inspectorate (17/00082-2/GRA), the Palestinian Health Research Council (reference no: BHRC। $\mathrm{HC} \backslash 13 \backslash 15)$ and the Regional Committee for Medical and Health Research Ethics in South-Eastern Norway, and was considered as a health quality research (REK 2014/1727). The Oslo University Hospital signed an agreement with the Palestinian Ministry of Health, which approved the conduct of the study within their facilities. The project was done in accordance with the common rules for healthcare services in Palestine and Norway regarding, for example, privacy. Verbal consents from the participating women were valid.

Provenance and peer review Not commissioned; externally peer reviewed. Data sharing statement № additional data are available.

Open access This is an open access article distributed in accordance with the Creative Commons Attribution Non Commercial (CC BY-NC 4.0) license, which permits others to distribute, remix, adapt, build upon this work non-commercially, and license their derivative works on different terms, provided the original work is properly cited, appropriate credit is given, any changes made indicated, and the use is non-commercial. See: http:// creativecommons.org/licenses/by-nc/4.0/. 


\section{REFERENCES}

1. Longo LD. Classic pages in obstetrics and gynecology. A treatise of midwifery. In three parts by Sir Fielding Ould, Dublin, O. Nelson \& C. Connor, 1742. Am J Obstet Gynecol 1976;124:656.

2. Myers-Helfgott MG, Helfgott AW. Routine use of episiotomy in modern obstetrics. Should it be performed? Obstet Gynecol Clin North Am 1999;26:305-25.

3. Jiang H, Qian X, Carroli G, et al. Selective versus routine use of episiotomy for vaginal birth. Cochrane Database Syst Rev 2017;2:Cd000081.

4. Reynolds JL. Reducing the frequency of episiotomies through a continuous quality improvement program. CMAJ 1995;153:275-82.

5. Ogunyemi D, Manigat B, Marquis J, et al. Demographic variations and clinical associations of episiotomy and severe perineal lacerations in vaginal delivery. J Natl Med Assoc 2006;98:1874-81.

6. Clesse C, Lighezzolo-Alnot J, De Lavergne S, et al. Statistical trends of episiotomy around the world: Comparative systematic review of changing practices. Health Care Women Int 2018;39:644-62.

7. Blondel B, Alexander S, Bjarnadóttir RI, et al. Variations in rates of severe perineal tears and episiotomies in 20 European countries: a study based on routine national data in Euro-Peristat Project. Acta Obstet Gynecol Scand 2016;95:746-54.

8. Hussein SA, Dahlen HG, Duff M, et al. The barriers and facilitators to evidence-based episiotomy practice in Jordan. Women Birth 2016;29:321-9.

9. Saadia Z. Rates and Indicators for Episiotomy in Modern Obstetrics a study from Saudi Arabia. Mater Sociomed 2014;26:188-90.

10. Fernandes S, Benjamin E, Edwards G. Using evidence to reduce the rate of episiotomy in a Dubai hospital. Evidence-Based Midwifery 2009; 7:60-3.

11. Wick L, Mikki N, Giacaman R, et al. Childbirth in Palestine. Int $J$ Gynaecol Obstet 2005;89:174-8.

12. Palestinian Central Bureau of Statistics. Press Conference on the Initial Survey Results: Demographic and Health Survey. RamallahPalestine: Palestinian Central Bureau of Statistics, 2004.

13. Hassan SJ, Sundby J, Husseini A, et al. Translating evidence into practice in childbirth: a case from the Occupied Palestinian Territory. Women Birth 2013;26:e82-9.
14. ACOG Practice Bulletin. Summary; Prevention and Management of Obstetric Lacerations at Vaginal Delivery No.165. Obstetrics and Gynecology 2016;128:411.

15. Tsvetkov D, Stoikov S, Lukanovich A. [Episiotomy--obstetrics operation with strict indications or iatrogenic injury of the female pelvic floor]. Akush Ginekol 2010;49:68-72.

16. Correa Junior MD, Passini Junior R, Indications Selective Episiotomy:. Technique and Association with Severe Perineal Lacerations. Rev. Bras. Ginecol. Obstet 2016;38:301-7.

17. Mercado J, Brea I, Mendez B, et al. Critical obstetric and gynecologic procedures in the emergency department. Emerg Med Clin North Am 2013;31:207-36.

18. RCOG. The management of Third and Fourth Degree Perineal Tears. Green-top Guideline 2015;29:2.

19. NICE. Intrapartum care: Care of healthy women and their babies during childbirth.2014. NICE clinical guideline 190. Manchester: NICE 2014.

20. World Health Organization. Intrapartum care for a positive childbirth experience. Geneva: WHO, 2018:150

21. Hassan S, Vikanes A, Laine $\mathrm{K}$, et al. Building a research registry for studying birth complications and outcomes in six Palestinian governmental hospitals. BMC Pregnancy Childbirth 2017;17:112

22. Ministry of Health. Health Status, Palestine 2015. Ramallah, State of Palestine: Ministry of Health, 2016:163.

23. Husic A, Hammoud MM. Indications for the use of episiotomy in Qatar. Int J Gynaecol Obstet 2009;104:240-1.

24. Obstetric Guidelines and Labor Ward protocols. Palestinian Ministry of Health and UNFPA. foruth edition, 2016:211.

25. Zimmo K, Laine K, Vikanes $\AA$, et al. Diagnosis and repair of perineal injuries: knowledge before and after expert training-a multicentre observational study among Palestinian physicians and midwives. BMJ Open 2017;7:e014183.

26. Abdul-Rahim HF, Abu-Rmeileh NM, Wick L. Cesarean section deliveries in the occupied Palestinian territory (oPt): an analysis of the 2006 Palestinian Family Health Survey. Health Policy 2009;93:151-6.

27. Borghi J, Fox-Rushby J, Bergel E, et al. The cost-effectiveness of routine versus restrictive episiotomy in Argentina. Am J Obstet Gynecol 2002;186:221-8. 